\title{
A long-term study of bone mineral density in patients with phenylketonuria under diet therapy
}

Hala M. Koura ${ }^{1}$, Nagwa Abdallah Ismail', Ashraf F. Kamel ${ }^{1}$, Azza M. Ahmed ${ }^{1}$, Amal Saad-Hussein², Laila K. Effat ${ }^{3}$

\begin{abstract}
1Department of Pediatric, National Research Centre, Cairo, Egypt
2Department of Environmental Research, National Research Centre, Cairo, Egypt

${ }^{3}$ Department of Molecular Genetic, National Research Centre, Cairo, Egypt
\end{abstract}

Submitted: 7 September 2010

Accepted: 5 December 2010

Arch Med Sci 2011; 7, 3: 493-500

DOI: 10.5114/aoms.2011.23417

Copyright @ 2011 Termedia \& Banach

\author{
Corresponding author: \\ Hala M. Koura MD \\ Pediatric Department \\ National Research Centre \\ El-Tahrir Street, Dokki, Egypt \\ Phone +20226706317, \\ Fax: +202 33370931 \\ E-mail: \\ Hala_koura@yahoo.com
}

\begin{abstract}
Introduction: Dietary control of classic phenylketonuria (PKU) needs restriction of natural proteins; adequate protein intake is achieved by adding low phenylalanine (phe) formulae. The adequacy of this diet for normal bone mineralization had not been sufficiently evaluated. Our aim was to evaluate and follow up bone mineral density (BMD) in children and adolescents with PKU within a 2-year time interval to assess the adequacy of a phenylalanine restricted diet for bone mineralization and to search for a possible relationship between BMD, dietary control and blood phenylalanine (phe) concentrations.

Material and methods: Thirty-two patients with classic PKU (3-19 years) were evaluated for their bone mineral status using dual energy X-ray absorptiometry (DEXA) both at the beginning (baseline) and the end (follow-up) of the study. Results: Low BMD was detected in $31.25 \%$ at the start and in $6.25 \%$ of patients after 2 years follows-up. No relationship was found between BMD and the duration of diet compliance and phe level as well.

Conclusions: In this study the low BMD detected in our patients was both at baseline and follow-up independent of diet restriction. A yearly DEXA would be highly beneficial for early detection and treatment, thus preventing osteoporosis and decreasing the risk of fractures. We also suggest the importance of searching for new emerging therapies such as enzyme substitution or gene therapy as low protein diet compliance was not enough to maintain normal bone mineral density.
\end{abstract}

Key words: phenylketonuria, osteoporosis, bone mineral density, diet.

\section{Introduction}

Phenylketonuria (PKU) is one of the first characterized metabolic diseases. Untreated PKU leads to mental retardation. Classical PKU results from impaired activity of the liver enzyme phenylalanine hydroxylase, which converts phenylalanine (phe) to tyrosine [1]. The advent of neonatal screening for PKU has enabled the start of a low phenylalanine diet early in life and the prevention of intellectual retardation associated with the disease [2].

Osteoporosis is increasingly being recognized in paediatric practice as a consequence of several factors including the increasing complexity of chronic conditions [3]. Several studies have suggested an increased risk of fractures [4] or a defect in bone mineralization in adults, adolescents and children with PKU [2, 5-13]. 
The aim of this study was to evaluate and follow up bone mineral density (BMD) in children and adolescents with PKU within a 2-year time interval to assess the adequacy of a phenylalanine restricted diet for bone mineralization and to search for a possible relationship between BMD, dietary control, and blood phenylalanine (phe) concentrations.

\section{Material and methods}

Our study included 32 patients with phenylketonuria recruited from the Association of Genetic and Metabolic Disorders and studied in the paediatric clinic of the National Research Centre (NRC).

Nineteen males and thirteen females were diagnosed clinically by fair hair and complexion, and developmental and mental retardation. A history of an affected sibling diagnosed with PKU developed the awareness in families to seek neonatal diagnosis. The diagnosis was confirmed by measurement of the blood phe level. The mean age of the patients was $8.6 \pm 4.7$ years, and at the end of the study was $10.7 \pm 4.9$ years. The study period was from January 2007 to January 2009. The selected patients were receiving a low protein diet consisting of low protein breads and pastas (wheat starch, Metamucil and methylcellulose), phenylalanine free formulas, fresh fruits and vegetables [14].

A control group of 42 age- and sex-matched Egyptian children was also included in the study. Informed consent was obtained from the parents of the children according to the guidelines of the ethical committee of NRC, Dokki, Egypt.

All patients were subjected to the following: detailed history and clinical examination including pedigree analysis noting the presence of consanguinity and family history of (PKU), age of diagnosis and duration of diet compliance, pattern of compliance (off diet, irregular or continuous compliance), and developmental milestones (namely: age of head support, mother recognition, sitting ,walking, and age of speech) [15]. The followup clinical visit for each patient was monthly, monitoring the growth status, phe level and diet compliance; diet adherence was determined based on the patient's report. Meticulous chest, heart, abdomen, and neurological examinations were done throughout the study period.

Anthropometric measurements: The weight was measured to the nearest $0.1 \mathrm{~kg}$ with a digital balance and with the patients in light clothes and without shoes. Height was measured to the nearest $0.5 \mathrm{~cm}$ with a stadiometer. Body mass index was calculated as weight divided by height squared for each patient $\left(\mathrm{kg} / \mathrm{m}^{2}\right)$. These parameters were adjusted to age and compared to Egyptian and CDC (Centre for Disease Control and Prevention) reference growth values and taken twice at the same time of each DEXA with statistical comparison between the 2 readings [16].

Bone mineral density and bone mineral content (BMC) were checked by dual-energy x-ray absorptiometry (DEXA) [17]. The Norland densitometer (XR-46, USA) Rev. 3.9.6/2.3.1 was used for BMD assessment. Oral sedation was required in 10 patients and the maximum time required for each evaluation was about 15 min. Bone mineral density for each patient was expressed in $\mathrm{g} / \mathrm{cm}^{2}$ and $\mathrm{BMC}$ in $\mathrm{g}$, both from the lumbar vertebrae $\left(\mathrm{L}_{2}-\mathrm{L}_{4}\right)$ and the femoral neck. Results were expressed as Z-score, the standard deviation (SD) from normal mean BMD for an age- and sex-matched Egyptian paediatric population. An abnormal DEXA was defined as more than one SD below the normal mean, expressed as Z-score < - 1 . Low BMD (osteopenia) was defined as Z-score from -1 to -2; very low BMD (severe osteopenia) was defined as $Z$-score from -2 to -2.5 and osteoporosis $<-2.5$ or spontaneous fracture $[13,18]$. The DEXA was done at baseline and follow-up study with statistical comparison between them.

Blood phenylalanine level was measured monthly by ELISA using the dried blood spot test. The mean of the two readings was recorded at the time of each DEXA with statistical comparison between them.

\section{Statistical analysis}

The results were computerized and analysed statistically using SPSS version 14.0. Results were expressed as means \pm standard deviation (SD). Independent $t$-test was used to compare between two groups and analysis of variance test (ANOVA) was used for the comparisons between more than two groups. Paired $t$-test was used to detect the changes in the quantitative data after diet for 2 years. Pearson correlation coefficient was used to determine the relationships between the quantitative variables. The level of significance was considered at $p$-value $<0.05$.

\section{Results}

The comparison between patients and controls at the start of this study for age, weight, height, body mass index (BMI), weight for age Z-score (WAZ), height for age Z-score (HAZ) and BMI percentiles is displayed in Table I. The WAZ and HAZ were significantly lower than controls $(p<0.005)$. Regarding the BMI percentile a statistical comparison was done between the Egyptian and CDC percentiles and the difference was not statistically significant (mean $50.4 \pm 5.18$ and 59.2 \pm 5.20 respectively in 2007 ; mean $62.2 \pm 4.17$ and $70 \pm 4.58$ respectively in 2009). The $p$ value in both was $>0.05$. 
The different parameters of the first DXA (patients and controls) are shown in Table II. A significant statistical difference was present in the femoral neck bone mineral density (FN-BMD), FN Z-score, and lumbar spine $\left(\mathrm{L}_{2}-\mathrm{L}_{4}\right) Z$-score, where the patients were significantly lower than the controls. The other parameters were also lower than controls but not statistically significant.

The comparison between the first and follow-up evaluation of growth and phe level is presented in Table III, showing a significant catch up of growth between the two readings except $H A Z$, in which improvement did not reach statistical significance. No significant statistical difference regarding the blood phe level was found.
The baseline and follow-up DXA are compared in Table IV, showing a significant statistical increase in all parameters except the lumbar Z-score, where $p>0.05$.

No correlation was found between growth (WAZ, HAZ) and phenylalanine (phe) levels and duration of diet compliance as well. Also no correlation was found between the blood phe level and BMD or $B M C$ in both evaluations.

The age of the patients at baseline and followup was positively correlated with the mean femoral and lumbar BMD, being $r=0.7, p \leq 0.0001$ and $r=0.9, p \leq 0.0001$ respectively. A significant inverse negative correlation was present between the age of the patients and the lumbar $\left(L_{2}-L_{4}\right) Z$-score in

Table I. Comparison of growth between patients and controls (first evaluation)

\begin{tabular}{|c|c|c|c|c|c|c|}
\hline Parameters & Type & $N$ & Mean & SD & $t$-Test & Value of $p$ \\
\hline \multirow[t]{2}{*}{ Age [years] } & PT & 32 & 8.6 & 4.7 & 0.036 & NS \\
\hline & C & 42 & 8.6 & 3.9 & & \\
\hline \multirow[t]{2}{*}{ Weight [kg] } & PT & 32 & 28.2 & 2.43 & 1.405 & NS \\
\hline & C & 42 & 33.0 & 2.41 & & \\
\hline \multirow[t]{2}{*}{ Height [cm] } & PT & 32 & 121.8 & 4.20 & 1.302 & NS \\
\hline & C & 42 & 128.4 & 2.89 & & \\
\hline \multirow[t]{2}{*}{ HAZ } & PT & 32 & -0.95 & 0.2 & 2.947 & $<0.005$ \\
\hline & C & 42 & -0.17 & 0.18 & & \\
\hline \multirow[t]{2}{*}{ WAZ } & PT & 32 & -0.3 & 0.22 & 3.032 & $<0.005$ \\
\hline & C & 42 & 0.61 & 0.2 & & \\
\hline \multirow[t]{2}{*}{ BMI $\left[\mathrm{kg} / \mathrm{m}^{2}\right]$} & PT & 32 & 17.8 & 0.49 & 1.454 & NS \\
\hline & C & 42 & 19.0 & 0.64 & & \\
\hline \multirow[t]{2}{*}{ BMI_percentile_Egypt } & PT & 32 & 50.4 & 5.18 & 1.752 & NS \\
\hline & C & 42 & 61.5 & 3.88 & & \\
\hline \multirow[t]{2}{*}{ BMI_percentile_CDC } & PT & 32 & 59.2 & 5.20 & 1.774 & NS \\
\hline & C & 42 & 70.6 & 3.96 & & \\
\hline
\end{tabular}

Table II. Bone mineral status (first evaluation)

\begin{tabular}{|c|c|c|c|c|c|c|}
\hline Parameters & Type & $N$ & Mean & SD & $t$-Test & Value of $p$ \\
\hline \multirow[t]{2}{*}{ FN_BMD [gm/cm²] } & PT & 32 & 0.6 & 0.03 & \multirow[t]{2}{*}{3.753} & \multirow[t]{2}{*}{$<0.0001$} \\
\hline & $\mathrm{C}$ & 42 & 0.7 & 0.02 & & \\
\hline \multirow[t]{2}{*}{ FN_BMC [gm] } & PT & 32 & 2.0 & 0.18 & \multirow[t]{2}{*}{1.833} & \multirow[t]{2}{*}{ NS } \\
\hline & $\mathrm{C}$ & 42 & 2.5 & 0.17 & & \\
\hline \multirow[t]{2}{*}{ FN_Z-score } & PT & 32 & -0.7 & 0.12 & \multirow[t]{2}{*}{5.421} & \multirow[t]{2}{*}{$<0.0001$} \\
\hline & $\mathrm{C}$ & 42 & 0.03 & 0.08 & & \\
\hline \multirow[t]{2}{*}{ BMD_L2_L4 } & PT & 32 & 0.5 & 0.03 & \multirow[t]{2}{*}{1.56} & \multirow[t]{2}{*}{ NS } \\
\hline & $\mathrm{C}$ & 42 & 0.6 & 0.02 & & \\
\hline \multirow[t]{2}{*}{ BMC_L2_L4 } & PT & 32 & 14.9 & 1.65 & \multirow[t]{2}{*}{1.239} & \multirow[t]{2}{*}{ NS } \\
\hline & $\mathrm{C}$ & 42 & 17.4 & 1.29 & & \\
\hline \multirow[t]{2}{*}{ Z-score_L2_L4 } & PT & 32 & -0.4 & 0.12 & \multirow[t]{2}{*}{2.638} & \multirow[t]{2}{*}{0.01} \\
\hline & $\mathrm{C}$ & 42 & 0.1 & 0.11 & & \\
\hline
\end{tabular}


Hala M. Koura, Nagwa Abdallah Ismail, Ashraf F. Kamel, Azza M. Ahmed, Amal Saad-Hussein, Laila K. Effat

Table III. Growth and Phe comparison at baseline and follow-up study

\begin{tabular}{|c|c|c|c|c|c|}
\hline & $N$ & Mean & SD & Paired $t$-test & Value of $p$ \\
\hline Weight_2007 & 32 & 28.2 & 2.43 & \multirow[t]{2}{*}{11.653} & \multirow[t]{2}{*}{$<0.0001$} \\
\hline Weight_2009 & 32 & 35.5 & 2.67 & & \\
\hline Height_2007 & 32 & 121.8 & 4.20 & \multirow[t]{2}{*}{14.337} & \multirow[t]{2}{*}{$<0.0001$} \\
\hline Height_2009 & 32 & 132.5 & 3.91 & & \\
\hline BMI_2007 & 32 & 17.8 & 2.75 & \multirow[t]{2}{*}{5.443} & \multirow[t]{2}{*}{$<0.0001$} \\
\hline BMI_2009 & 32 & 19.2 & 3.06 & & \\
\hline BMI_percentile_CDC_2007 & 32 & 59.2 & 5.20 & \multirow[t]{2}{*}{2.797} & \multirow[t]{2}{*}{$<0.01$} \\
\hline BMI_percentile_CDC_2009 & 32 & 70.3 & 4.58 & & \\
\hline Egyptian BMI percentile 2007 & 32 & 51.8 & 5.13 & \multirow[t]{2}{*}{2.479} & \multirow[t]{2}{*}{$<0.05$} \\
\hline Egyptian BMI percentile 2009 & 32 & 62 & 4.17 & & \\
\hline WAZ 2007 & 32 & -0.29 & 0.22 & \multirow[t]{2}{*}{3.116} & \multirow[t]{2}{*}{$<0.005$} \\
\hline WAZ 2009 & 32 & 1.12 & 0.57 & & \\
\hline HAZ 2007 & 32 & -0.95 & 2 & \multirow[t]{2}{*}{$1.306^{*}$} & \multirow[t]{2}{*}{ NS } \\
\hline HAZ 2009 & 32 & 0.18 & 0.65 & & \\
\hline Phe [mg/dl] 2007 & 32 & 12.3 & 0.95 & \multirow[t]{2}{*}{0.8} & \multirow[t]{2}{*}{ NS } \\
\hline Phe [mg/dl] 2009 & 32 & 11.7 & 0.98 & & \\
\hline
\end{tabular}

*Wilcoxon signed ranks test (Z-test)

Table IV. Bone mineral status at baseline and follow-up study

\begin{tabular}{|c|c|c|c|c|c|}
\hline & $N$ & Mean & SD & Paired $t$-test & Value of $p$ \\
\hline FN_BMD 2007 & 32 & 0.6 & 0.03 & 8.97 & $<0.0001$ \\
\hline FN_BMD 2009 & 32 & 0.7 & 0.02 & & \\
\hline FN_BMC 2007 & 32 & 2.0 & 0.18 & 5.048 & $<0.0001$ \\
\hline FN_BMC 2009 & 32 & 2.4 & 0.19 & & \\
\hline FN_Z-score_2007 & 32 & -0.7 & 0.12 & 2.777 & $<0.01$ \\
\hline FN_Z-score_2009 & 32 & -0.5 & 0.10 & & \\
\hline BMD_L2_L4_2007 & 32 & 0.5 & 0.03 & 9.959 & $<0.0001$ \\
\hline BMD_L2_L4_2009 & 32 & 0.6 & 0.03 & & \\
\hline BMC_L2_L4_2007 & 32 & 14.9 & 1.65 & 9.312 & $<0.0001$ \\
\hline BMC_L2_L4_2009 & 32 & 19.1 & 1.82 & & \\
\hline Z-score_L2_L4_2007 & 32 & -0.4 & 0.12 & 1.378 & NS \\
\hline Z-score_L2_L4_2009 & 32 & -0.2 & 0.10 & & \\
\hline
\end{tabular}

2009 ( $r=-0.4, p \leq 0.05)$. No correlation was found between the duration of dietary compliance and lumbar and femoral BMD and its Z-scores in both evaluations. The individual progression of the femora and lumbar Z-scores on both occasions is shown in Figures 1 and 2 and Table V. It can be seen that femoral BMD Z-score declined in 9/32 patients (28\%); 4/9 were off diet, 3/9 were irregularly compliant and 2/9 were strictly diet adherent; for the lumbar area $11 / 32$ patients (34.37\%) had a decreased lumbar Z-score; 4/11 were off diet, $3 / 11$ strictly diet adherent, and 4/11 were irregularly compliant.
At baseline, femoral osteopenia was present in 10 patients (31.25\%) and 3/10 had osteopenia of the lumbar area as well; 5/10 were under the age of 7 years, and the other $5 / 10$ aged from 9 to 16 years. Five $(5 / 10)$ patients were on a strict diet, $3 / 10$ were off diet, and 2/10 were irregularly compliant. At follow-up, improvement with an increase in Z-score was present in all 10 patients. Another 2 patients (6.25\%), 19 and 21 years old, were not osteopenic at the start of the study but developed osteopenia $(-1.11$ and -1.8) at the end of the study.

Among the osteopenic patients 5/10 were given oral drug supplement (calcium + vitamin $D_{3}$ ) in 


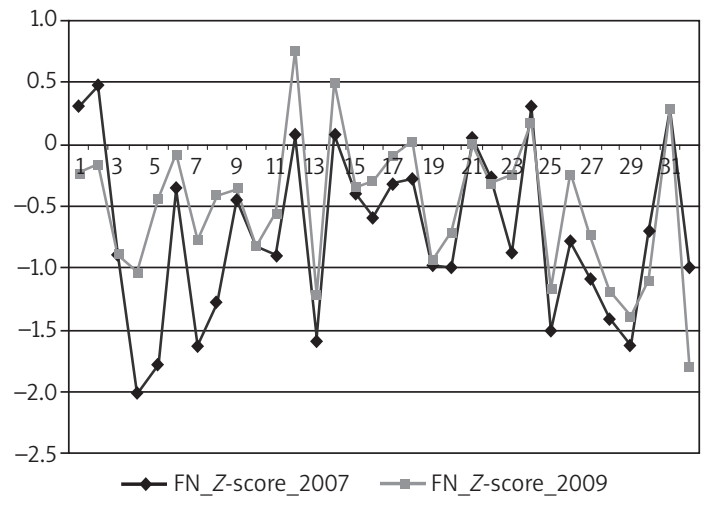

Figure 1. Femoral Z-score at baseline and follow-up

addition to diet control and showed an improvement of their BMD Z-score from $-1.7,-1.63$, $-1.29,-1.50$, and -1.10 in the first evaluation to $0.43,-0.76,-0.41,-1.17$, and -0.72 in the second evaluation. Only one patient remained osteopenic. The rest of osteopenic patients refused to take the drug supplement and showed a slower rate of improvement from $-2.02,1.56,-1.01,-1.42,-1.63$ to $-1.05,-1.22,-0.7,-1.2,-1.4$. Four patients remained in the osteopenic region.

Clinically, there was a delay in the different developmental milestones in the group of patients, with mean age of head support $1.2 \pm 0.93$ years, age of mother recognition $1.6 \pm 1.6$ years, age of sitting $1.3 \pm 0.95$ years, age of walking $2.6 \pm 1.3$ years. The duration of diet compliance (mean $2.3 \pm 2.1$ years) was associated with a significant inverse negative correlation with the blood phe level both at the start and follow-up $(r=-0.05, p<0.001$ and $r=-0.05$, $p<0.005)$ respectively. The mean age of diagnosis was $1.8 \pm 1.4$ years ( 1 week-4 years); 9 patients were diagnosed early (the first 6 months of life); 5 of them were diagnosed in the neonatal period (positive history in a sib); 4 of those 5 were on a strict low protein diet and are mentally normal, attending regular schools.

Concerning the pattern of patient compliance, 11 of them (34.37\%) were not compliant (off diet), $12(37.5 \%)$ were partially compliant with some period of relaxation (irregular pattern) and $9(28.12 \%)$ had a strict continuous pattern of compliance. The age of speech for the 3 groups was: no speech present in the off-diet group (only a few words), $1.8 \pm 0.40$ years in the irregular group and $2 \pm 0.78$ years in the continuous group.

The blood phe levels showed a significant statistical difference between the 3 groups, where the smallest value was in the continuously compliant group; in 2007 the mean was 16.4 $\pm 1.15 \mathrm{mg} / \mathrm{dl}$ in the off group, $13 \pm 0.94 \mathrm{mg} / \mathrm{dl}$ in the irregular group and $6.3 \pm 1.2 \mathrm{mg} / \mathrm{dl}$ in the continuously compliant group ( $F$-ratio $=20.572$, $p \leq 0.0001)$. In 2009, the mean was $14.6 \pm 1.32 \mathrm{mg} / \mathrm{dl}$

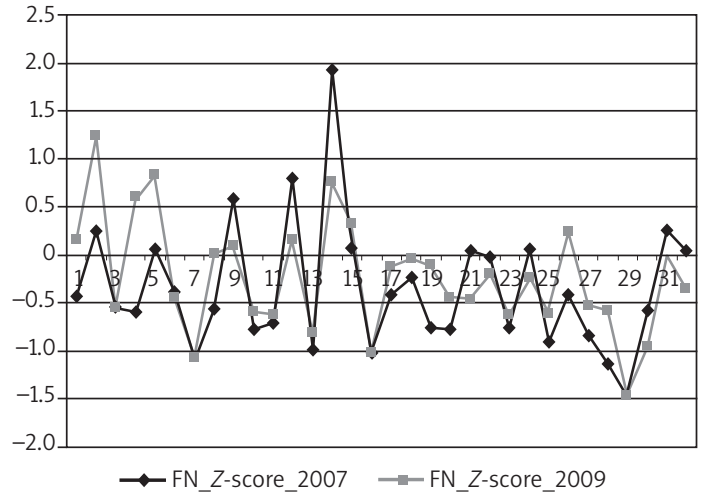

Figure 2. Lumbar Z-score at baseline and follow-up

in the off group, $14.2 \pm 1.01 \mathrm{mg} / \mathrm{dl}$ in the irregular group and $4.9 \pm 0.75 \mathrm{mg} / \mathrm{dl}$ in the continuously compliant group (F-ratio 23.214, $p \leq 0.0001$ ).

A marked improvement of milestones and symptoms with diet (as reported by the patients) was noted in the compliant groups, both irregular and continuous (e.g. mother recognition, sitting, walking, and speech). No statistically significant difference was found between the 3 groups regarding the femoral and lumbar BMD and BMC together with their Z-scores.

Neurological examination at the start of the study was normal in most patients apart from hypotonia, which was detected in only one patient (3.33\%), hypertonia in 4 patients (12.5\%) and exaggerated knee jerk in only one patient (3.33\%). These signs disappeared by the end of the study except the hypotonia, which remained in the same patient (off diet). Examination of other systems revealed no abnormality.

\section{Discussion}

With any dietary manipulation involving elimination of key nutrients as in PKU it is essential that the replacement therapy is adequate to ensure normal growth and that the patients are monitored long term for adverse effects [2]. Our results confirmed the reduced bone mineralization in children and adolescents with PKU compared with controls as reported by other authors [2, 7, 9, 11-13], who confirmed the lower BMD in children and adolescents with classical PKU on a standard dietary regime. The mean femoral and lumbar BMD $Z$-scores were significantly lower than the controls and osteopenia was detected in $31.25 \%$ of our patients in the femoral neck. These findings were similar to those of Modan-Moses (2007) [13], who found osteopenia in at least one skeletal site in $38.7 \%$ of his patients and reported that trabecular bone mass as represented by the femoral neck density was severely affected. In contrast to the findings of Modan-Moses [13] none of our patients 
Table V. Femoral and lumbar Z-scores of the baseline and follow-up study

\begin{tabular}{|c|c|c|c|c|}
\hline \multirow[t]{2}{*}{ Ranks } & & \multirow[t]{2}{*}{$N$} & \multicolumn{2}{|c|}{ Wilcoxon signed ranks test } \\
\hline & & & $Z$ test & Sig \\
\hline \multirow[t]{3}{*}{ FN_Z-score_2007 - FN_Z-score_2009 } & Negative ranks & 9 & 2.656 & $<0.01$ \\
\hline & Positive ranks & 23 & & \\
\hline & Ties & 0 & & \\
\hline \multirow[t]{3}{*}{ Z-score_L2_L4_2007 - Z-score_L2_L4_2009 } & Negative ranks & 11 & 1.45 & NS \\
\hline & Positive ranks & 19 & & \\
\hline & Ties & 2 & & \\
\hline
\end{tabular}

Positive ranks - improvement, negative rank - declined Z-score, Ties - no change

had osteoporosis with BMD Z-score $<-2.5$. The current study was done on children and adolescents with PKU, while his study included adult PKU patients with a mean age of $25 \pm 5.3$ years [13]. The difference may also be related to different geographical areas, as reported by Cowell (1995) [19], who evaluated 24 PKU patients (1-20 years) in his geographical area for osteopenia, but no abnormalities in lumbar BMD were found.

Vitamin and trace element deficiency may contribute to osteopenia in PKU patients, although phe-free protein formulas are enriched with vitamins, minerals and trace elements; iron and $B_{12}$ depletion as well as low zinc and selenium levels have been reported in PKU patients. Furthermore, calcium, folate, thiamine, niacin, and vitamin $B_{6}$ intake may be up to $60 \%$ lower than the recommended amounts in this patient group [20], which was confirmed by our results where half of the osteopenic patients were on a strict low protein diet with adequate formula intake.

The follow-up DEXA showed declined femoral and lumbar Z-scores in $28 \%$ and $34.4 \%$ of patients, respectively, almost equally to our three groups of diet compliance. These different patterns of compliance in relation to BMD proved, as found by other authors [21, 22], that diet control of PKU patients is difficult and hypomineralization in those patients needs to be clarified [13]. Furthermore, the numbers of patients who decide to stop dietary treatment increases gradually with age [23].

Half of the osteopenic patients were given oral calcium and vitamin D supplement and showed improvement of their BMD Z-score more than those who did not take the supplement. This was supported by Pérez-Dueñas (2002) [10], who found improvement of BMD of six PKU patients with a low dose of vitamin D. In addition, these patients were improved due to adequate sun exposure as the main source of vitamin D in Mediterranean countries is cutaneous synthesis from UV radiation [10].

Although the osteopenia was detected first in the femoral neck, we, like other authors [5], found a significant negative correlation of lumbar BMD $Z$-score with age, indicating that the lumbar spine is more prone to the development of osteopenia and/or osteoporosis with age. BMD measured by DEXA in the lumbar spine was the technique of choice for most authors because it has a high precision in vivo and permits monitoring of treatment in the lumbar spine, which is a very sensitive area for changes in BMD [2, 8, 12].

Data about the relation of BMD to diet are conflicting; as reported by other authors [10, 12], we found no correlation between BMD and dietary control, reflected either by blood phe concentrations or the duration of compliance; however, other investigators reported that lack of dietary compliance and phe level > $19.8 \mathrm{mg} / \mathrm{dl}$ were associated with a decrease in BMC [9]. Many patients in the present study showed variation in blood phe level; this was in keeping with Barat (2002), who suggested that this variation may contribute to osteopenia in PKU patients [6]. Zeman et al. (1999) suggested that mutations in the phenylalanine hydroxylase gene might inherently predispose PKU patients to osteoporosis although the potential mechanism for this is unknown [12], which was nearly in agreement with our study, in which we could not identify any specific causative factor for osteopenia.

At the start of the study growth retardation was observed in our PKU patients in comparison with controls, like Dobbelaere (2003), who found his PKU patients shorter and lighter than the reference population [24]. European studies [25-29] found similar growth retardation during the first years of life followed by restoration of the normal growth curve from the second year or later, supporting our results that $65.6 \%$ of the patients were under 10 years of age and all of them showed a significant catch up of growth at the follow-up study. In agreement with other authors, we found no correlation between phe levels and growth [24, 25, $30,31]$. However, it is clear that the outcome of growth in PKU patients depends on the therapeutic approach, genetic background and novel alimentary substitutes. An international study comparing and evaluating these differences between centres would be extremely interesting [24]. 
Although delayed developmental milestones were observed in our patients mostly due to delay in age of diagnosis, a phenylalanine restricted diet was introduced immediately after diagnosis as it may reduce the burden of disabilities even at a late stage [32-34].

In conclusion, a compromised bone mineral density was detected at baseline and follow-up study in our patients; potential contributing factors include dietary deficiency of protein, calcium, vitamin $D$ or trace elements or a primary defect in bone turnover inherent to the disease itself; our data do not favour any one particular factor.

We suggest further large-scale studies to illustrate the mechanism of low BMD in PKU patients together with annual follow-up DEXA for early detection and treatment to prevent osteoporosis and decrease the risk of fractures later in life. Moreover, and since low BMD was detected both at baseline and follow-up studies, we recommend the importance of searching for new emerging therapies such as enzyme substitution or gene therapy since low protein diet compliance was not sufficient to maintain normal bone mineral density.

\section{References}

1. Kahler SG, Fahey MC. Metabolic disorders and mental retardation. Am J Med Genet 2003; 117: 31-41.

2. Allen JR, Humphries IR, Waters DL, et al. Decreased bone mineral density in children with phenylketonuria. Am J Clin Nutr 1994; 59: 419-22.

3. Shaw NJ. Osteoporosis in pediatrics. Arch Dis Child Educ Pract 2007; 92: 169-75.

4. Greeves LG, Carson DJ, Magee A, Patterson C. Fractures and phenylketonuria. Acta Paediatr 1997; 86: 242-4.

5. Al-Qadreh A, Schulpis KH, Athanasopoulou H, Mengreli C, Skarpalezou A, Voskaki I. Bone mineral status in children with phenylketonuria under treatment. Acta Paediatr 1998; 87: 1162-6.

6. Barat P, Barthe N, Redonnet-Vernhet I, Parrot F. The impact of the control of serum phenylalanine levels on osteopenia in patients with phenylketonuria. Eur J Pediatr 2002; 161: 687-8.

7. Carson DJ, Greeves LG, Sweeney LE, Crone MD. Osteopenia and phenylketonuria. Pediatr Radiol 1990; 20: 598-9.

8. Hillman L, Schlotzhauer C, Lee D, et al. Decreased bone mineralization in children with phenylketonuria under treatment. EurJ Pediatr 1996; 155 (Suppl I): S148-52.

9. McMurry MP, Chan GM, Leonard CO, Ernst SL. Related bone mineral status in children with phenylketonuriarelationship to nutritional intake and phenylalanine control. Am J Clin Nutr 1992; 55: 997-1004.

10. Pérez-Dueñas B, Cambra FJ, Vilaseca MA, Lambruschini N, Campistol J, Camacho JA. New approach to osteopenia in phenylketonuric patients. Acta Paediatr 2002; 91: 899-904.

11. Schwahn B, Mokov E, Scheidhauer K, Lettgen B, Schonau $E$. Decreased trabecular bone mineral density in patients with phenylketonuria measured by peripheral quantitative computed tomography. Acta Paediatr 1998; 87: 61-3.
12. Zeman J, Bayer M, Stepán J. Bone mineral density in patients with phenylketonuria. Acta Paediatr 1999; 88: 1348-51.

13. Modan-Moses D, Vered I, Schwartz G, et al. Peak bone mass in patients with phenylketonuria. J Inherit Metab Dis 2007; 30: 202-8.

14. Virginia E. Schnett. Low protein cookery for phenylketonuria. 3rd ed. University of Wisconin 1997; 43-478.

15. Rutter M. Nature, nurture, and development: from evangelism through science toward policy and practice. Child Dev 2002; 73: 1-21.

16. Seidell JC, Doak CM, de Munter JS, Kuijper LD, Zonneveld $\mathrm{C}$. Cross sectional growth references and implications for the development of an international growth standard for school-aged children and adolescents. Food Nutr Bull 2006; 27 (Suppl Growth Standard): S189-98.

17. Abd ElBaky A, Ismail N, Salama E, Abou-Zekri M, Fatouh A, Ragab R. Inappropriate restriction of dietary gluten and associated bone acquisition and bone density in Egyptian children with coeliac disease. Arch Med Sci 2009; 5: 589-95.

18. Ward LM, Glorieux FH. The spectrum of pediatric osteoporosis. In: Glorieux FH, Pettifor JM, Jüppner H (eds.). Pediatric bone: biology and diseases. San Diego, CA: Academic Press 2003; 401-42.

19. Cowell CT, Lu PW, Lloyd-Jones SA, et al. Volumetric bone mineral density - a potential role in paediatrics. Acta Pediatr Suppl 1995; 411: 12-6.

20. Przyrembel H, Bremer HJ. Nutrition, physical growth, and bone $\mathrm{V}$ density in treated phenylketonuria. EurJ Pediatr 2000; 159 (Suppl 2): S129-135.

21. Campistol J, Vilaseca MA, Cambra J, Lambruschini N. Diagnostico, tratamient o y seguimient o de las hiperfenilalaninemias. Act Nutr 1998; 24: 22-9.

22. Schulz B, Bremer HJ. Nutrient intake and food consumption of adolescents and young adults with phenylketonuria. Acta Pediatr 1995; 84: 743-8.

23. Aoki K, Ohwada M, Kitagawa TJ. Long-term follow-up study of patients with phenylketonuria detected by the newborn screening programme in Japan. Inherit Metab Dis 2007; 30: 608-13.

24. Dobbelaere D, Michaud L, Debrabander A, et al. Evaluation of nutritional status and pathophysiology of growth retardation in patients with phenylketonuria. J Inherit Metab Dis 2003; 26: 1-6.

25. Schafer F, Burgard P, Batzler U, et al. Growth and skeletal maturation in children with phenylketonuria. Acta Paediatr 1994; 83: 534-41.

26. Van der Schot LW, Doesburg WH, Sengers WCA. The phenylalanine response curve in relation to growth and mental development in the first years of life. Acta Paediatr 1994; 407: 68-9.

27. Verkerk PH, van Spronsen FJ, Smit GPA, Sengers RCA. Impaired prenatal and postnatal growth in Dutch patients with phenylketonuria. Arch Dis Child 1994; 71: 114-8.

28. Allen JR, Baur LA, Waters DL, et al. Body protein in prepubertal children with phenylketonuria. Eur J Clin Nutr 1996; 50: 178-86.

29. Dhondt JL, Largillière C, Moreno L, Farriaux JP. Physical growth in patients with phenylketonuria. $32^{\text {nd }}$ Annual Symposium of the Society for the Study of Inborn Errors of Metabolism, Edinburgh (Abstract) 1994.

30. Acosta PB, Yannicelli S, Marriage B, et al. Nutrient intake and growth of infants with phenylketonuria undergoing therapy. J Pediatr Gastroenterol Nutr 1998; 27: 287-91.

31. Arnold GL, Vladutiu CJ, Kirby RS, Blakely EM, DeLuca JM. Protein insufficiency and linear growth restriction in phenylketonuria. J Pediatr 2002; 141: 243-6. 
32. Yannicelli S, Ryan A. Improvements in behaviour and physical manifestations in previously untreated adults with phenylketonuria using a phenylalanine restricted diet: a national survey. J Inherit Metab Dis 1995; 18: 131-4.

33. Fitzgerald B, Morgan J, Keene N, Rollinson R, Hodgson A, Dalrymple-Smith J. An investigation into diet treatment for adults with previously untreated phenylketonuria and severe intellectual disability. I Intellect Disabil Res 2000; 44: 53-9.

34. Koch R, Moseley K, Ning J, Romstad A, Guldberg P, Guttler. Long-term beneficial effects of the phenylalaninerestricted diet in late-diagnosed individuals with phenylketonuria. Mol Genet Metab 1999; 67: 148-55. 